\title{
Yolk-shell structured silicon/carbonized polyacrylonitrile composites as anode materials for lithium-ion batteries
}

\author{
Xiaohui Gong ${ }^{1,3}$, Shengping Cao $^{2}$, Zhipeng Qiao ${ }^{3}$, Hui Wen ${ }^{1}$, Baoping Lin $^{1}$, and Yueming Sun ${ }^{1, *}$ \\ ${ }^{1}$ School of Chemistry and Chemical Engineering, Southeast University, Nanjing 211189, P. R. China \\ ${ }^{2}$ Jiangsu Baichuan High-Tech New Materials Co. Ltd., Jiangyin 214422, P. R. China \\ 3 Jiangsu Higee Energy Co. Ltd., Jiangyin 214422, P. R. China \\ *E-mail: 220081994@ seu.edu.cn
}

doi: $10.20964 / 2021.06 .16$

Received: 16 October 2020 / Accepted: 3 March 2021 / Published: 30 April 2021

\begin{abstract}
Silicon is a potential anode material for high-energy lithium-ion batteries because of its extremely high theoretical capacity. The most critical issue for the application of silicon anodes is the fast capacity fade caused by the large volume variation of silicon during lithiation and delithiation processes. In this study, silicon/carbon composites agglomerated from yolk-shell silicon@void@pyrolysis carbon particles were prepared by coating aluminum-silicon alloy particles with polyacrylonitrile and subsequently dissolving the aluminum from the carbonized composites in a ferric chloride etchant. The use of a proper amount of the hydrolyzed polyacrylonitrile as a binder in the coating process is beneficial to reduce the structural defects of the composites. The void space between the carbon shell and silicon core formed by removing the aluminum can accommodate the expanded silicon and thus stabilize the composite structures. As a result, the silicon/carbon composites exhibit considerably better cell performances, especially chargedischarge cycling stabilities, than the powder mixture of silicon and pyrolytic carbon. The composite with few structural defects maintained a reversible capacity of more than $500 \mathrm{mAh} \mathrm{g}^{-1}$ after 50 cycles at a current density of $0.1 \mathrm{C}$, while the silicon component in the powder mixture lost almost all of its capacity after only a few cycles.
\end{abstract}

Keywords: lithium-ion batteries; silicon/carbon composite; polyacrylonitrile; yolk-shell

\section{$\underline{\text { FULL TEXT }}$}

(C) 2021 The Authors. Published by ESG (www.electrochemsci.org). This article is an open access article distributed under the terms and conditions of the Creative Commons Attribution license (http://creativecommons.org/licenses/by/4.0/). 